\title{
Pengaruh Konsentrasi Leachate Terhadap Pertumbuhan Tanaman Uji
}

\author{
Irhamni $^{1,2^{*}}$, Setiaty Pandia ${ }^{3}$, Edison Purba ${ }^{4}$, Wirsal Hasan ${ }^{5}$ \\ ${ }^{1}$ Program Studi Pengelolaan Sumber Daya Alam dan Lingkungan, USU, Medan \\ ${ }^{2}$ Fakultas Teknik Universitas Serambi Mekkah \\ ${ }^{3}$ Fakultas Teknik Kimia, USU, Medan \\ ${ }^{4}$ Fakultas Pertanian, USU, Medan \\ ${ }^{5}$ Fakultas Kesehatan Masyarakat, USU, Medan \\ *Koresponden email : Irhamni@ serambimekkah.ac.id
}

Diterima: 30 November 2019

Disetujui: 12 Desember 2019

\begin{abstract}
Poor landfill management and not in accordance with the rules raises serious problems of liquid waste (leachate). One alternative treatment of heavy metal contaminated waste is phytoremediation techniques with aquatic plants. The purpose of this study was to determine the effect of growth on Typha Latifolia test plants using leachate concentrations. The study used the concentration method for diluting V1.N1 = V2.N2 and Regression. The leachate concentrations used were 20\%, 40\%,60\%, 80\% and 100\% and control. Observation data focused on the number of tillers, root length, leaf length and number of leaf petals. The results obtained from the observation data the higher the leachate concentration, the lower the number of tillers, root length, number of leaves and number of leaf petals in Typha latifolia test plants. This proves that Typha latifolia plants are hyperaccumulator plants that can grow on leachate.
\end{abstract}

Keywords: landfill, leachate concentration, phytoremediation, typha latifolia, hyperaccumulator

\begin{abstract}
Abstrak
Pengelolaan TPA yang buruk dan tidak sesuai kaidah menimbulkan permasalahan serius limbah cair (leachete). Salah satu alternatif pengolahan limbah terkontaminasi logam berat adalah teknik fitoremediasi dengan tumbuhan air. Tujuan penelitian untuk mengetahui pengaruh pertumbuhan terhadap tanaman uji Typha Latifolia dengan menggunakan konsentrasi leachate. Penelitian menggunakan metode konsentrasi untuk pengenceran $\mathrm{V}_{1} \cdot \mathrm{N}_{1}=\mathrm{V}_{2} \cdot \mathrm{N}_{2}$ dan Regresi. Konsentrasi leachate yang digunakan adalah $20 \%, 40 \%, 60 \%, 80 \%$ dan 100\% dan kontrol. Data pengamatan terfokus pada jumlah anakan, panjang akar, panjang daun dan jumlah kelopak daun. Hasil yang diperoleh dari data pengamatan semakin tinggi konsentrasi leachate, maka semakin rendah baik jumlah anakan, panjang akar, jumlah daun dan jumlah kelopak daun pada tumbuhan uji Typha latifolia. Ini membuktikan tumbuhan Typha latfolia sebagai tumbuhan hyperaccumulator yang dapat tumbuh di leachate.
\end{abstract}

Kata Kunci: TPA, konsentrasi leachate, fitoremediasi, typha latifolia, hyperaccumulator

\section{Pendahuluan}

Ada beberapa tumbuhan hidroponik mengeluarkan enzim berupa bahan kimia yang dapat mempercepat proses degradasi. Enzim ini diperlukan oleh tumbuhan terutama pada sejumlah biomassa dan area permukaan akar pada media hidroponik [1,2]. Tumbuhan hiperakumulator adalah tumbuhan yang mempunyai kemampuan untuk mengakumulasi logam di dalam biomassa dalam kadar yang luar biasa tinggi. Kebanyakan tumbuhan mengakumulasi logam setara dengan 0,001\%, tetapi tumbuhan hiperakumulator mampu mengakumulasi hingga 11\% Berat Kering. Dengan batas kadar logam yang terdapat di dalam biomassa agar suatu tumbuhan dapat disebut hiperakumulator berbeda - beda bergantung pada jenis logamnya [3].

Air lindi (leachate) di Tempat Pemrosesan Akhir (TPA) disebabkan terjadinya presipitasi cairan ke TPA, baik dari resapan air hujan maupun kandungan air pada sampah itu sendiri. Lindi bersifat toksik karena adanya zat pengotor dalam timbunan yang mungkin berasal dari buangan limbah industri, debu, lumpur hasil pengolahan limbah, limbah rumah tangga yang berbahaya atau dari dekomposisi yang normal terjadi pada sampah. Apabila tidak segera diatasi, landfill yang dipenuhi air lindi dapat mencemari lingkungan, terutama air tanah dan air permukaan $[4,5]$. Air lindi pada umumnya mengandung senyawasenyawa organik dan anorganik. Konsentrasi dari komponen-komponen tersebut dalam air lindi lebih tinggi daripada konsentrasi dalam air tanah. Selayaknya benda cair, air lindi ini akan mengalir ke tempat 
yang lebih rendah dan dapat merembes ke dalam tanah serta bercampur dengan air tanah, ataupun mengalir di permukaan tanah, dan bermuara pada aliran air sungai. Sehingga dapat dibayangkan potensi air lindi yang mengandung senyawa-senyawa organik (hidrokarbon) dan anorganik (logam berat) dengan konsentrasi sekitar lebih tinggi daripada dalam air tanah, masuk dan mencemari air tanah atau air sungai. Secara langsung, air tanah atau air sungai tersebut akan tercemar [6,5].

Persoalan yang umumnya terjadi akibat pengelolaan sampah yang kurang baik di sekitar TPA antara lain adalah tercemarnya udara, tanah dan air (air tanah maupun air permukaan) sebagai akibat dari lindi [7,2]. Faktor utama konsentrasi nutrien dalam larutan tanah dan transpor ke akar tumbuhan adalah pH tanah, unsur-unsur pembentukan khelat dan kecepatan penguapan. Akumulasi logam oleh tumbuhan bergantung pada banyak faktor yaitu :

a) Sifat alamiah tumbuhan, seperti: spesies, kecepatan tumbuh, ukuran dan kedalaman akar, kecepatan penguapan, serta kebutuhan nutrien untuk metabolisme,

b) Faktor tanah, seperti: $\mathrm{pH}$, kandungan dan sifat alamiah zat organik, status nutrien, jumlah ionion logam dan anion-anion tertentu seperti fosfat, sulfat, kadar mineral lempung, dan tipe tanah, dan

c) Variabel-variabel lingkungan dan pengelolaan yaitu temperatur, kelembaban, sinar matahari, curah hujan, pemupukan dan lain-lain.

Jenis tumbuhan air di Indonesia sangat beraneka ragam dan hampir semuanya memiliki kemampuan untuk menyerap limbah misalnya: Typha sp, Ipomeous sp, Eichornia crassipies dan lain-lain. Typha latifolia yang merupakan tumbuhan yang dapat hidup pada kondisi wetland. Tumbuhan ini dapat digolongkan kepada jenis tumbuhan hiperakumulator. Kemampuan tumbuhan Typha latifolia dalam menyerap logam berat besar, menjadikan tumbuhan ini digunakan sebagai alternatif dalam menyerap limbah logam [8,9].

Tumbuhan air lainnya yang dapat menyerap logam berat adalah Salvonella mullestam [10,11] Anturium Merah/Kuning, Alamanda Kuning/Ungu, Akar Wangi, Bambu Air, Cana Presiden Merah/Kuning/Putih, Dahlia, Dracenia Merah/Hijau, Heleconia Kuning/Merah, Jaka, Keladi Loreng/Hitam, Lotus Kuning/Merah [12,13], Padi-padian, Papirus, Pisang Mas, Spider Lili, dan lainnya $[14,15]$, yang banyak ditemukan di daerah persawahan dan genangan air. Sayuran merupakan salah satu jenis tumbuhan yang juga dapat menyerap logam berat dari tanah.

Kebanyakan logam berat berkumpul di bagian akar tumbuhan, termasuk sayuran berdaun, berbuah, dan berubi, seperti Sawi (Brassica nigra), Tembikai (Citrullus lonatus), Labu (Cucurbita moshata) dan Ubi kayu (Manihot esculenta) [16]. (Typha latifolia) seperti yang terlihat pada Gambar 1 merupakan tumbuhan dari suku Typhaceae dan bangsa Typhales yang mempunyai rizoma, beramilum, sering membentuk koloni padat, menjulamg dari air dangkal atau tumbuh di tempat yang basah, sel-sel bertanin tersebar, batang tegak, serta berakhir dengan pembungaan. Daun berbentuk dua garis, kebanyakan di dasar, pelepah laminalinearis. Habitat dari Typha latifolia ini adalah lingkungan yang mempunyai nilai $\mathrm{pH} 4-10$ dan temperatur $10-30^{\circ} \mathrm{C}$.

TumbuhanTypha latifolia dapat ditemukan di rawa dan wetland yang terdapat di hampir setiap benua. Tumbuhan Typha latifolia adalah salah satu tumbuhan yang dapat hidup pada kondisi wetland. [17]. Tumbuhan ini banyak kita jumpai pada daerah tropis dan biasanya Typha latifolia tumbuh berkelompok pada daerah yang tergenang air. Tumbuhan Typha latifolia memiliki daya tahan yang tinggi terhadap perubahan cuaca dan kondisi lingkungan lainnya.
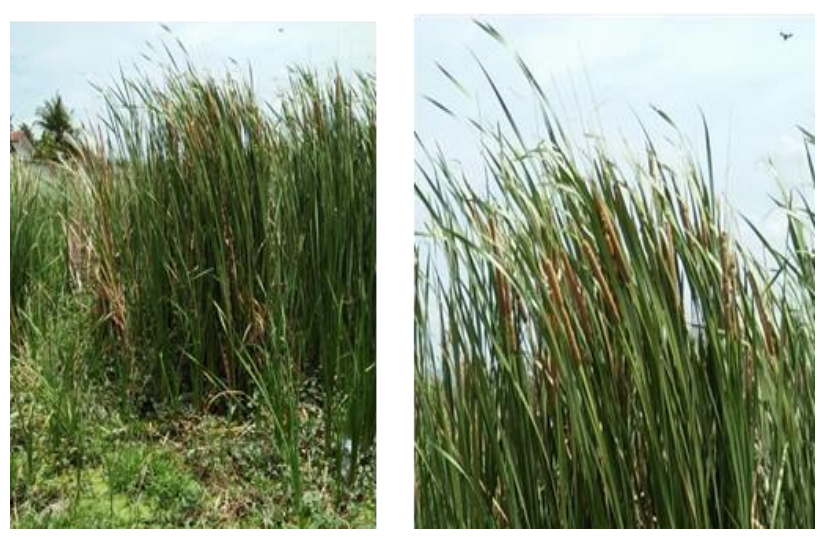

Gambar 1. Typha latifolia [5] 
Typha latifolia membutuhkan air yang banyak untuk mendukung pertumbuhannya. Tumbuhan Typha latifolia yang juga mendukung berlangsungnya suatu ekologi dan kontrol biotik. Hal ini dapat kita lihat dari begitu banyaknya binatang yang hidup di dalam komunitas tumbuhan Typha latifolia.

\section{Metode Penelitian}

Lokasi penelitian di Gampong Peurada Kecamatan Syiah Kuala dan TPA Keudah, Kota Banda Aceh. Bahan baku penelitian ini adalah media limbah cair/lindi dengan konsentrasi $20 \%, 40 \%, 60 \%$, $80 \%$, dan $100 \%$ serta media kontrol diperlukan sebagai pembanding. Tumbuhan uji meliputi Typha latifolia (tumbuhan obor). Untuk melihat konsentrasi leachate terbaik pada pertumbuhan tumbuhan uji dalam limbah cair atau leachate dilakukan pengamatan jumlah anakan, panjang akar, jumlah daun dan jumlah kelopak daun dan setiap minggu diukur dengan menggunakan alat ukur. Pengamatan dilakukan dalam 4 minggu. Alat- alat yang digunakan terdiri dari wadah penampung tumbuhan (drum), lindi/leachate, ember, kertas label, alat ukur dan kamera. Untuk setiap pertumbuhan tanaman dilihat pada jumlah anakan, panjang akar, jumlah daun dan jumlah kelopak daun. Pengolahan data menggunakan Statistik program SPSS dan uji lanjut DMRT [13]. Variabel tetap ukuran reaktor : tinggi $40 \mathrm{~cm}$, lebar 23 cm dan panjang $30 \mathrm{~cm}$.

Variabel Bebas:
(a) Umur Tanaman
(b) Waktu Tumbuh
: 1 bulan $(\geq 50 \mathrm{~cm})$
(c) Konsentrasi Leachate
: $0,1,2,3$, dan 4 minggu
: $20,40,60,80$, dan $100 \%$

$$
\begin{gathered}
\mathrm{V}_{1} \cdot \mathrm{N}_{1}=\mathrm{V}_{2} \cdot \mathrm{N}_{2} \ldots \ldots \ldots \ldots \ldots \ldots \ldots \ldots \\
\mathrm{Yij}=\mu+\alpha \mathrm{j}+\beta \mathrm{K}+(\alpha \beta) \mathrm{jk}+\varepsilon \mathrm{ijk}
\end{gathered}
$$

\section{Hasil Dan Pembahasan}

\section{a. Jumlah Anakan}

Pengaruh konsentrasi leachate terhadap pertumbuhan Typha latifolia diamati selama 4 minggu pada konsentrasi lindi berbeda yaitu $20 \%, 40 \%, 60 \%, 80 \%$ dan 100\%. Hasil pengamatan terhadap jumlah anakan, panjang akar, panjang daun dan jumlah kelopak daun dapat dilihat pada Gambar 2.

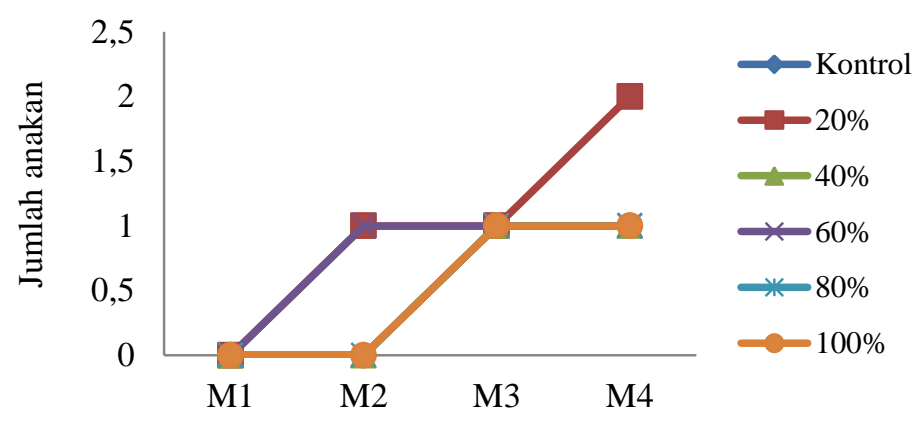

Waktu (Minggu)

Gambar 2. Jumlah anakan

Jumlah anakan Typha latifolia bertambah pada semua perlakuan konsentrasi lindi, jumlah anakan bertambah hanya 1 pada tiap konsentrasi kecuali pada konsentrasi $20 \%$ penambahan anakan selama perlakuan adalah 2 anakan baru. Hasil pengamatan pengaruh lindi terhadap jumlah anakan Typha latifolia pada tiap perlakuan dapat dilihat pada Tabel 1. 
Tabel 1. Jumlah anakan

\begin{tabular}{ccccc}
\hline Konsentrasi Lindi & \multicolumn{4}{c}{ Waktu Pengamatan (Minggu) } \\
\cline { 2 - 5 }$(\%)$ & 1 & 2 & 3 & 4 \\
\hline 20 & 0 & 1 & 1 & 2 \\
40 & 0 & 0 & 1 & 1 \\
60 & 0 & 1 & 1 & 1 \\
80 & 0 & 0 & 1 & 1 \\
100 & 0 & 0 & 1 & 1 \\
Kontrol & 0 & 0 & 1 & 1 \\
\hline
\end{tabular}

Untuk melihat hubungan pengaruh konsentrasi terhadap jumlah anakan Typha latifolia, maka dilakukan uji analisis dengan uji statistik analisis varian (Tabel 2).

Tabel 2. Jumlah anakan

\begin{tabular}{|ll|r|r|r|r|r|}
\hline \multirow{2}{*}{ Model } & \multicolumn{2}{|c|}{$\begin{array}{c}\text { Unstandardized } \\
\text { Coeff icients }\end{array}$} & \multicolumn{2}{c|}{$\begin{array}{c}\text { Standardized } \\
\text { Coeff icients }\end{array}$} & & \\
\cline { 3 - 5 } & & $\mathrm{B}$ & Std. Error & \multicolumn{1}{c|}{ Beta } & \multicolumn{1}{c|}{$\mathrm{t}$} & \multicolumn{1}{c|}{ Sig. } \\
\hline 1 & (Constant) & 1.800 & .383 & & 4.700 & .018 \\
& Kadar Lindi & -.010 & .006 & -.707 & -1.732 & .182 \\
\hline
\end{tabular}

a. Dependent Variable: Jumlah anakan Typha latifolia

Berdasarkan hasil analisis statistik menunjukkan bahwa nilai nilai regresi linier yaitu koefisien $\mathrm{R}$ sebesar 0,707 dengan arah hubungan negatif yang berarti semakin tinggi konsentrasi lindi, maka semakin rendah jumlah anakan pada tumbuhan Typha latifolia. Uji signifikan pada uji t diperoleh nilai $\mathrm{p}$ value yaitu 0,182 , nilai ini masih diatas 0,05 sehingga belum menghasilkan suatu hubungan yang signifikan pada tingkat kesalah tersebut. Namun besarnya koefisien R yang didapat sudah menggambarkan besarnya pengaruh konsentrasi lindi terhadap pertumbuhan jumlah anakan tumbuhan uji tersebut (Typha latifolia).

\section{b. Panjang Akar}

Gambar 3 menunjukkan kenaikan grafik pertumbuhan pada konsentrasi 20\%, 40\% dan 60\%. Kenaikan tersebut menunjukkan adanya penambahan panjang akar Typha latifolia. Data hasil pengamatan selama waktu perlakuan dapat dilihat pada Tabel 3.

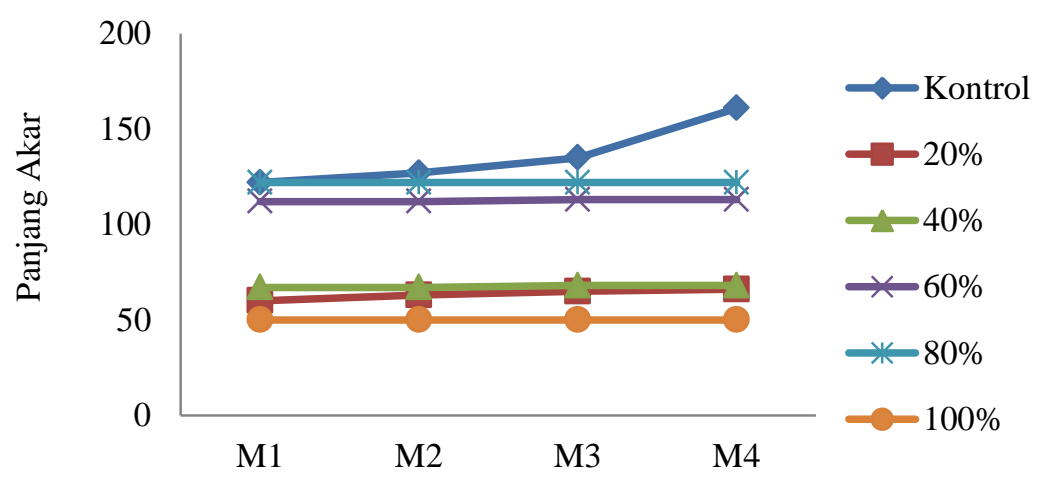

Waktu (Minggu)

Gambar 3. Panjang akar

Tabel 3. Panjang akar

\begin{tabular}{ccccc}
\hline Konsentrasi & \multicolumn{4}{c}{ Waktu Pengamatan (Minggu) } \\
\cline { 2 - 5 } Lindi $(\%)$ & 1 & 2 & 3 & 4 \\
\hline 20 & 30 & 30 & 32 & 34 \\
40 & 13 & 14 & 14 & 15 \\
60 & 11 & 11 & 11 & 12 \\
80 & 13 & 13 & 13 & 13 \\
100 & 5 & 5 & 5 & 5 \\
Kontrol & 10 & 29 & 34 & 52 \\
\hline
\end{tabular}


Pertambahan panjang akar pada Typha latifolia terjadi pada konsentrasi $20 \%$, 40\% dan $50 \%$. Namun pertambahan panjang akar tersebut sangat sedikit dan tidak signifikan. Pertambahan panjang akar ini dimulai pada minggu ke 2 sampai minggu ke 4 kecuali pada konsentrasi $60 \%$ pertumbuhan panjang akar tidak terjadi pertambahan panjang akar setelah minggu ke 3, sedangkan pada konsentrasi tinggi (80\% dan $100 \%$ ) tidak mengalami pertambahan perpanjangan akar dari perlakuan minggu ke 1 sampai minggu ke 2. Hal ini menunjukkan bahwa konsentrasi lindi berpengaruh terhadap panjang akar Typha latifolia. Untuk membuktikan hubungan tersebut, maka dilakukan uji analisis varian pengaruh hubungan antara konsentrasi lindi terhadap panjang akar Typha latifolia (Tabel 4).

Tabel 4. Panjang akar

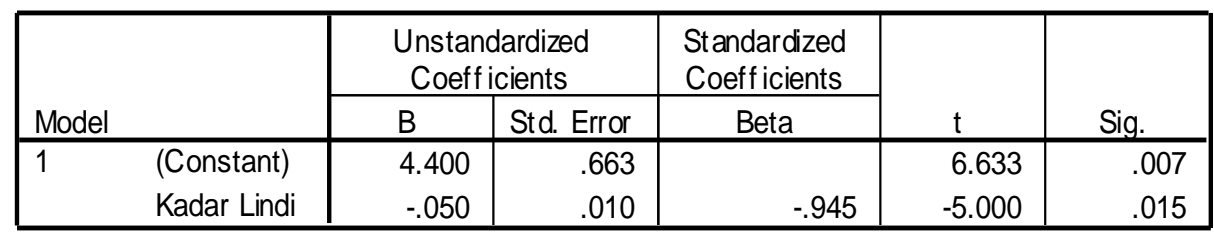

a. Dependent Variable: Panjang akar Ty pha latif olia

Hasil analisis varian Tabel 4 menunjukkan hasil regresi (koefisien) R sebesar 0,945 dengan arah hubungan negatif yang berarti, semakin tinggi konsentrasi lindi maka semakin rendah pertumbuhan panjang akar Typha latifolia. Uji signifikan berdasarkan uji t diperoleh $\mathrm{p}$ value sebesar 0,015 yaitu dibawah 0,05 sehingga belum menghasilkan suatu hubungan yang signifikan pada tingkat kesalahan tersebut. Namun besarnya koefisien $\mathrm{R}$ yang diperoleh sudah menggambarkan besarnya pengaruh konsentrasi lindi terhadap panjang akar Typha latifolia.

\section{c. Panjang Daun}

Pengaruh konsentrasi lindi terhadap panjang daun Typha latifolia selama perlakuan dapat dilihat pada Gambar 4.

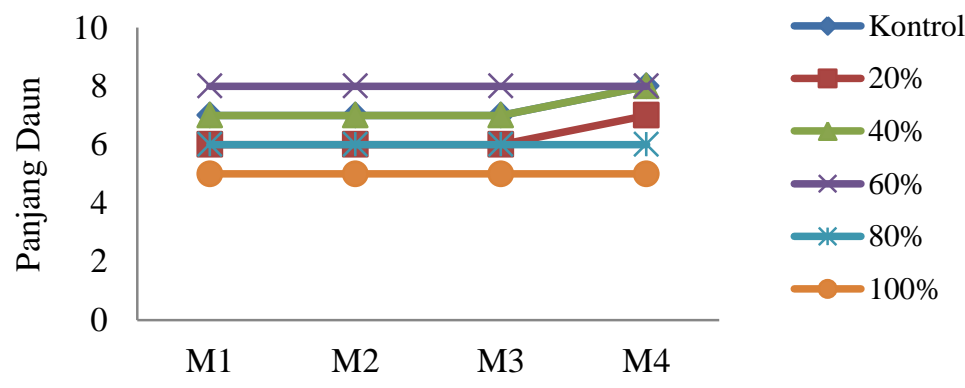

Waktu (Minggu)

Gambar 4. Panjang daun

Pengaruh konsentrasi lindi terhadap pertambahan panjang daun pada Typha latifolia menunjukkan grafik konstan pada konsentrasi tinggi $80 \%$ dan $100 \%$, yang artinya tidak mengalami pertambahan panjang daun. Pada konsentrasi rendah 20, 40 dan 60\% grafik sedikit naik yang artinya terjadi pertambahan panjang daun Typha latifolia. Pengaruh konsentrasi lindi terhadap panjang daun Typha latifolia dapat dilihat pada Tabel 5.

Tabel 5. Panjang daun

\begin{tabular}{ccccc}
\hline Konsentrasi & \multicolumn{4}{c}{ Waktu Pengamatan (minggu) } \\
\cline { 2 - 5 } Lindi (\%) & 1 & 2 & 3 & 4 \\
\hline 20 & 60 & 63 & 65 & 66 \\
40 & 67 & 67 & 68 & 68 \\
60 & 112 & 112 & 113 & 113 \\
80 & 122 & 122 & 122 & 122 \\
100 & 50 & 50 & 50 & 50 \\
Kontrol & 122 & 127 & 135 & 161 \\
\hline
\end{tabular}


Pertambahan panjang daun Typha latifolia terbaik terjadi pada konsentrasi $20 \%$, yaitu naik pada minggu ke 2 hingga minggu ke 4 . Pada konsentrasi $40 \%$ dan $60 \%$ pertambahan panjang daun hanya terjadi pada minggu ke 3, sedangkan pada konsentrasi $80 \%$ dan $100 \%$ tidak terjadi pertambahan panjang daun dari pengamatan minggu ke 1 sampai minggu ke 4 . Untuk melihat pengaruh konsentrasi lindi terhadap panjang daun Typha latifolia di lakukan analisis varian, hasil uji adalah Tabel 6.

Tabel 6. Panjang daun

\begin{tabular}{|c|c|c|c|c|c|}
\hline \multirow[b]{2}{*}{ Model } & \multicolumn{2}{|c|}{$\begin{array}{l}\text { Unstandardized } \\
\text { Coeff icients }\end{array}$} & $\begin{array}{l}\text { Standardized } \\
\text { Coeff icients }\end{array}$ & \multirow[b]{2}{*}{$t$} & \multirow[b]{2}{*}{ Sig. } \\
\hline & $\mathrm{B}$ & Std. Error & Beta & & \\
\hline $\begin{array}{ll}1 & \text { (Constant) } \\
& \text { Kadar Lindi } \\
\end{array}$ & $\begin{array}{r}5.500 \\
-.065 \\
\end{array}$ & $\begin{array}{r}1.745 \\
.026 \\
\end{array}$ & -.819 & $\begin{array}{r}3.153 \\
-2.472 \\
\end{array}$ & $\begin{array}{l}.051 \\
.090 \\
\end{array}$ \\
\hline
\end{tabular}

a. Dependent Variable: Panjang daun Typha latif olia

Hasil regresi dari analisis varian diperoleh koefisien $\mathrm{R}$ yaitu 0,819 dengan arah hubungan negatif yang berarti semakin tinggi konsentrasi lindi maka kemampuan pertambahan panjang daun semakin kecil. Uji signifikan berdasarkan uji $t$ diperoleh nilai $\mathrm{p}$ value 0,090 , nilai ini masih diatas 0,05 sehingga belum menghasilkan suatu hubungan yang signifikan pada tingkat kesalahan tersebut. Namun besarnya koefisien $\mathrm{R}$ yang diperoleh sudah menggambarkan besarnya pengaruh konsentrasi lindi terhadap panjang daun Typha latifolia.

\section{d. Jumlah Kelopak Daun}

Pengaruh konsentrasi lindi terhadap jumlah kelopak daun Typha latifolia selama perlakuan dapat dilihat pada Gambar 5.

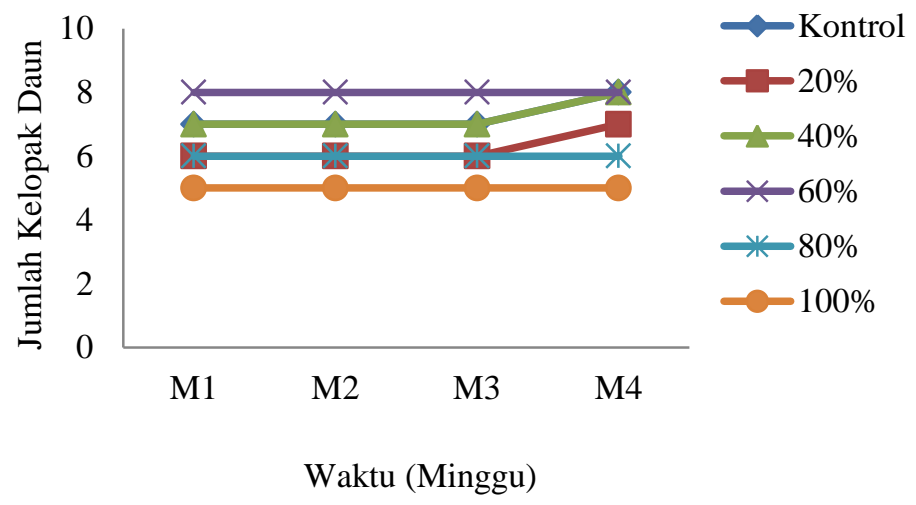

Gambar 5. Jumlah kelopak daun

Pada Gambar 5 dapat dilihat bahwa pada konsentrasi rendah yaitu 20\% dan 40\% pada minggu ke 3, yang artinya ada penambahan jumlah kelopak daun Typha latifolia. Sedangkan pada konsentrasi tinggi $60 \%, 80 \%$ dan $100 \%$ grafik cenderung tetap, yang artinya tidak terjadi penambahan jumlah kelopak daun pada konsentrasi ini. Hasil data pengamatan selama perlakuan dapat dilihat pada Tabel 7.

Tabel 7. jumlah kelopak daun

\begin{tabular}{cllll}
\hline Konsentrasi & \multicolumn{4}{c}{ Waktu Pengamatan (Minggu) } \\
\cline { 2 - 5 } Lindi (\%) & 1 & 2 & 3 & 4 \\
\hline 20 & 6 & 6 & 6 & 7 \\
40 & 7 & 7 & 7 & 8 \\
60 & 8 & 8 & 8 & 8 \\
80 & 6 & 6 & 6 & 6 \\
100 & 5 & 5 & 5 & 5 \\
Kontrol & 7 & 7 & 7 & 8 \\
\hline
\end{tabular}

Penambahan jumlah kelopak daun Typha latifolia selama perlakuan tidak menunjukkan penambahan berarti, hanya terdapat pada konsentrasi lindi rendah yaitu pada $20 \%$ dan $40 \%$. Masingmasing konsentrasi hanya bertambah 1 kelopak daun yaitu pada minggu ke 4 perlakuan. Sedangkan pada 
konsentrasi lindi tinggi $(60 \%, 80 \%$ dan $100 \%)$ tidak terjadi penambahan kelopak daun dari awal hingga akhir perlakuan. Untuk melihat hubungan kosentrasi lindi terhadap jumlah kelopak daun dilakukan uji statistik analisis varian. Hasil uji dapat dilihat pada Tabel 8.

Tabel 8. jumlah kelopak daun

\begin{tabular}{|c|c|c|c|c|c|c|}
\hline \multirow{2}{*}{\multicolumn{2}{|c|}{ Model }} & \multicolumn{2}{|c|}{$\begin{array}{l}\text { Unstandardized } \\
\text { Coeff icients }\end{array}$} & \multirow{2}{*}{$\begin{array}{c}\begin{array}{l}\text { Standardized } \\
\text { Coefficients }\end{array} \\
\text { Beta } \\
\end{array}$} & \multirow[b]{2}{*}{$\mathrm{t}$} & \multirow[b]{2}{*}{ Sig. } \\
\hline & & $B$ & Std. Error & & & \\
\hline \multirow[t]{2}{*}{1} & (Constant) & 1.300 & .332 & & 3.920 & .030 \\
\hline & Kadar Lindi & -.015 & .005 & -.866 & -3.000 & .058 \\
\hline
\end{tabular}

a. Dependent Variable: Jumlah kelopak Typha latifolia

Berdasarkan hasil regresi linier antara pengaruh konsentrasi lindi terhadap jumlah kelopak daun Typha Latifolia, diperoleh nilai $\mathrm{R}$ sebesar 0,866 dengan arah hubungan negatif yang berarti semakin tinggi kadar lindi, maka semakin rendah jumlah kelopak daun tumbuhan tersebut. Namun uji signifikan berdasarkan uji $t$ diperoleh nilai $p$ value 0,058 yang masih diatas 0,05 sehingga belum menghasilkan suatu hubungan yang signifikan pada tingkat kesalahan tersebut. Namun besarnya koefisien $\mathrm{R}$ yang didapat sudah menggambarkan besarnya pengaruh kadar lindi terhadap pertumbuhan jumlah kelopak.

\section{Kesimpulan}

Berdasarkan hasil penelitian dapat ditarik kesimpulan semakin rendah baik jumlah anakan, panjang akar, jumlah daun dan jumlah kelopak daun pada tumbuhan uji Typha latifolia. Namun besarnya koefisien $\mathrm{R}$ yang didapat sudah menggambarkan besarnya pengaruh konsentrasi leachate terhadap pertumbuhan tumbuhan uji Typha latifolia. Ini membuktikan tumbuhan Typha latifolia sebagai tumbuhan hyperaccumulator yang dapat tumbuh di air yang terkontaminasi limbah cair atau leachate di TPA.

\section{Daftar Pustaka}

[1] The Used Of Aquatic Wetland Plant Phylidrum lanuginosum To Remove Lead From Aqueous Solution, Faculty of Applied Science, University technology MARA Shah Alam, Selangor, Malaysia

[2] Heavy metal content in final disposal garbage site at Banda Aceh City. Journal of Physics: Conference Series Volume 1116 Issue 4 Hal. 042014. DOI:10.1088/1742-6596/1116/4/042014

[3] Fitoremediasi Sebagai Sebuah Teknologi Pemulihan Pencemaran, Khususnya Logam Berat. TRIPOD, IPAL Biotech, Ipal Biofilter, Wwtp Ipal Rs, Ipal Industri

[4] Phytoremediation Waste Mercury Using Plant And System Reactor, Jurnal Ilmiah Sain Vol. 14 No.1.

[5] Fitoremediasi Berbasis Tumbuhan Air Untuk Penerapan Beberapa Logam Berat (Cr, Hg, Pb), ISBN:978-602-0898-49-0

[6] Skripsi Profil Penyebaran Logam Berat Di Sekitar TPA Pakusari Jember

[7] Merkuri: Bahaya, Sumber Pencemar, Dan Pengelolaannya di Lingkungan. Kampanye dan sosialisasi Dampak Merkuri Terhadap Lingkungan. Meulaboh, 9 Desember 2013

[8] Phytoremediation of heavy metal polluted soils and water. J. Zhejiang Univ Sci B, March: 9(3): 210220

[9] Zinc Lead and Cadmium Tolerance, Uptake and Accumulation by Typha Latifolia, Department of Biology, Hongkong Baptist University, Kowloon Tong, Hongkong

[10] Pythoremediation of Cadmium and Chromium Contaminated Soils By Cyperus Rotundus. L,J.AURSTEM (97-101), ISSN (Online):2328-3580.

[11] Pengukuran Karbon Tersimpan di Berbagai Macam Penggunaan Lahan. World Agroforestry Center. Bogor.

[12] Efisiensi Fitoremediasi pada Air Terkontaminasi $\mathrm{Cu}$ menggunakan Salvinia molesta mitchal. Di dalam: Prosiding Seminar Biologi. Kediri. (Vol. 10, No. 1).

[13] Statistik, Konsep Dasar dan Aplikasinya, Prenada Media, Rawamangun,

[14] Analisis Manajemen Tempat Pemrosesan Akhir (TPA) Gampong Jawa Kota Banda Aceh Sebagai Stasiun Pemilihan, Jurnal Teknik sipil, ISSN:2302-0253, Vol 4, No 1, 18-20 
[15] Metals Adsorptions on Leachate by Activated Carbon, Zeolite, and Silica Gel in TPA Tlekung, Batu, Jurnal Sumberdaya Alam dan Lingkungan, hal 44-48

[16] Phytoremediation: a green technology to remove environmental pollutants. American Journal of Climate Change, vol. 2, pp. 71-86

[17] Karakteristik air lindi (leachate) di tempat pembuangan akhir sampah air dingin kota padang Jurnal Fisika Unand Vol. 6, No. 1, Januari 2017. (93-99) ISSN 2302-8491 